\title{
Ethnopharmacology and Computer-Aided Tandem Protocol to Search for Antimalarial Agents from Indonesian Medicinal Plants: HAP Inhibitor
}

\author{
Adinda Kusuma Pertiwi, Muhammad Habiburrohman, Yoshinta Debby, Bawon Triatmoko, Ari \\ Satia Nugraha*
}

Drug Utilisation and Discovery Research Group, Faculty of Pharmacy, University of Jember, Jember, Indonesia 68121

${ }^{*}$ Corresponding author:

E-mail:arisatia@unej.ac.id

\begin{abstract}
The anti-malarial potency of Indonesian medicinal plants was evaluated through computational study. From 43 Indonesian medicinal plants, 238 previously reported compounds were carefully docked into HAP (histo-aspartic protease) with codename 3FNT in which the enzyme plays an important catalytic role in Plasmodium falciparum innate metabolism. Exhaustive docking experiments produced 6 best hits molecules including AM210 (4-hydroxy- 3-methoxy strychnine), AM213 (protostrychnine), and AM216 (pseudostrychnine) which have less free energy compared to HAP native ligand, 1,2-ethanediol. This study revealed the potency of Strychnos nux-vomica L. as a source for antimalaria and support its traditional claims.
\end{abstract}

Keywords: HAP inhibitor, Molecular docking, Antimalaria, Striychnos nux-vomica

\section{Introduction}

Malaria is a disease transmitted through the bites of a female Anopheles mosquito containing Plasmodium parasite in its body. Malaria is one of the deadly and epidemic diseases in the world. In 2012 around 207 million people were affected by malaria with around 627,000 people dead. Africa accounts for $90 \%$ of deaths with $77 \%$ are children less than 5 years old (Teng et al., 2019). In addition to fatalities, malaria had an impact on the economic sector too, it is estimated that the African continent has lost nearly \$ 100 billion in GDB over 35 years due to malaria (Go, 2005). Indonesia is also affected by this life-threatening tropical disease, some areas in Indonesia are still at high risk of affected malaria such as West Papua and NTT (Elyazar, Hay, \& Baird, 2011).

Located in the equatorial region, Indonesia has the second-largest biodiversity country in the world after Brazil. Indonesia has around 25,000-30,000 plant species which constitute $80 \%$ of the world's total plant species and $90 \%$ of the plant species in Asia (Erdelen, Adimihardja, \& Moesdarsono, 1999; Pramono, 2002). "Senarai Tumbuhan Obat Indonesia" published by the Health Department of Indonesia in 1986 documented 940 plants as medicinal plants (Health Department of Indonesia, 1986). Ethnobotanically, some of these medicinal plants are used against malaria, but many medicinal plants have not been studied for their activity against malaria. Unfortunately, a study related to drug derivatives from plants in Indonesia is not optimal.

One of the potential targets of antimalarial drug intervention is hemoglobin metabolism in the erythrocytic stage. Histo-aspartic protease (HAP) is an aspartic protease or plasmepsin enzyme that plays a role in hemoglobin degradation to amino acids and hemozoin. Amino acids from hemoglobin proteolysis is very important in the cycle life of Plasmodium for protein biosynthesis and energy metabolism, in addition to the limitations of Plasmodium in the synthesis of de novo amino acids. On the other hand, hemozoin is a product of the detoxification of heme which is toxic to

How to cite:

Pertiwi, A. K., Habiburrohman, M., Debby, Y., Triatmoko, B., \& Nugraha, A. S. (2021). Ethnopharmacology and computer-aided tandem protocol to search for antimalarial agents from Indonesian medicinal plants: HAP Inhibitor. The 3rd International Conference on Life Sciences and Biotechnology. NST Proceedings. pages 9-16. doi: 10.11594/ nstp.2021.0802 
themselves (Ersmark, Samuelsson, \& Hallberg, 2006). Therefore, inhibition of the HAP enzyme can be a potential target in the discovery of anti-malaria drugs.

The developments of high-throughput protein purification, crystallography, and nuclear magnetic resonance spectroscopy techniques have been contributed to many structural details of proteins and protein-ligand complexes. These developments enable computational strategies to permeate all aspects of drug discovery such as virtual screening (VS) techniques (Gohlke \& Klebe, 2002). Compared to traditional experimental high-throughput screening (HTS), VS is a more direct and rational drug discovery approach and has low-cost and effective screening. VS can be classified into ligand-based and structure-based methods. Molecular docking is a structure-based drug design and the most widely used method since the early 1980s (Kuntz et al., 1982). The molecular docking approach can be used to model interactions between small molecules and proteins at the atomic level, which allows us to characterize the behavior of small molecules at the target protein binding site and to explain the fundamental biochemical processes (McConkey, Sobolev, \& Edelman, 2002). This study aimed to reveal the potency of Indonesian medicinal plants as a source for antimalarial agents.

\section{Material and Methods \\ Materials}

The hardware used was SONY with an Intel Core i5-2430M Processor $2.40 \mathrm{GHz}$ and Windows 7 Home Premium 64-bit operating system. The software used was Chem Draw Ultra 12.0 which is used to draw ligand structures in 2D. For visualization of 3D molecules and minimize energy through MM2 calculations in Chem3D 12. Autodock software was used for ligand and protein preparation. Autodock vina was used to process molecular docking. PyMOL was used for visualization and analysis of interactions between ligands and enzymes. The structure of the 3D enzyme used in this study was the HAP (histo-aspartic protease) enzyme. The enzyme was downloaded from the protein data bank (GDP) (https://rcsb.org). Also, we obtained a molecular database structure (https://pubchem. ncbi.nlm.nih.gov).

\section{Enzyme preparation}

The HAP enzyme was downloaded from the protein data bank (https://rcsb.org) with codename 3FNT and through Chem3D 12 all the water molecules were removed, the enzyme separated from the original ligand using the PyMOL. Then the enzyme was prepared by adding hydrogen polar using autodock tools. The target enzyme was ready for the molecular docking process.

\section{Ligand preparation}

The native ligand was obtained from the website of Protein Data Bank (PDB) (https://rcsb.org). 238 compounds for molecular docking were obtained from previously reported secondary metabolites of 43 Indonesian medicinal plants used traditionally as antimalaria. These compounds are secondary metabolites obtained from Scifinder database searching (https://scifinder.cas.org), drawn in 2D and minimized energy using the MM2 method and saved in the PDB file extension. The method used in minimizing energy was the 'force field molecular mechanism MM2' method. Then the ligands were prepared through autodock tools and save as a.PDBQT file extension.

\section{Griding}

Griding was used to determine the right region enzyme for docking. In this study, we used the original ligand as a reference for the ligand dock. This process used autodock tools. 


\section{Molecular docking}

The molecular docking process used Vina autodock software. Enzyme and ligand files with the extension pdbqt were saved in one folder as many as 238 folders according to the number of compounds. Then added "conf.txt", a text with the extension .txt containing the file name, and the griding region of the position attached to the ligand.

\section{Visualization}

The docked ligands then visualized using the Pymol software. This software can read various enzyme and ligand extensions. Also, from the Pymol software, interactions between the ligand and its enzyme is obtained in free energy of binding $(\Delta G)$ score.

\section{Results and Discussion}

Molecular docking is a computational procedure that predicts the non-covalent binding of macromolecules (target proteins) with small molecules (ligands) efficiently. This prediction is important for the development of compounds suspected of having a biological activity to be used as a guiding compound for a lead drug discovery (Trott \& Olson, 2010). This procedure was successful to reveal the antimalarial potency of secondary metabolites isolated from medicinal plants $(\mathrm{Pu}-$ jiastuti et al., 2014).

Previously, the docking protocol was valid as indicated by the Root Mean Square Deviation (RMSD) value of $1.434 \AA$. RMSD is a parameter used to see the similarity between docking ligand and crystallographic ligand. A good RMSD value is less than 2 , where the smaller value of RMSD the higher similarity between docking ligand and crystallographic. The results of the 238 compilation tests in the HAP enzyme experiment were reviewed based on the large bonds and binding sites.

Free energy of binding $(\Delta G)$ is a parameter of a drug's ability to bind to a receptor as a marker of affinity and amino acid residues (Pratama \& Aziz, 2019; Pratama \& Gusdinar, 2017). The smaller value of $\Delta \mathrm{G}$, the higher affinity between the receptor and the ligand. Meanwhile, the positive and negative values of $\Delta \mathrm{G}$ indicate that the reaction is exothermic or endothermic. The complex bond between ligand and receptor in a negative direction indicates that the reaction is exothermic wherein the reaction is released several energy (heat). The smaller or more negative $\Delta G$ of the ligand complex with the receptor means less energy needed to react so that ligands can easily replace native ligand bonds. From the molecular docking process, it was found that almost all compounds had a good $\Delta \mathrm{G}$ score, in table 1 . The 6 ligands were presented with the best $\Delta \mathrm{G}$ score.

Table 1. Ligands Hit to HAP

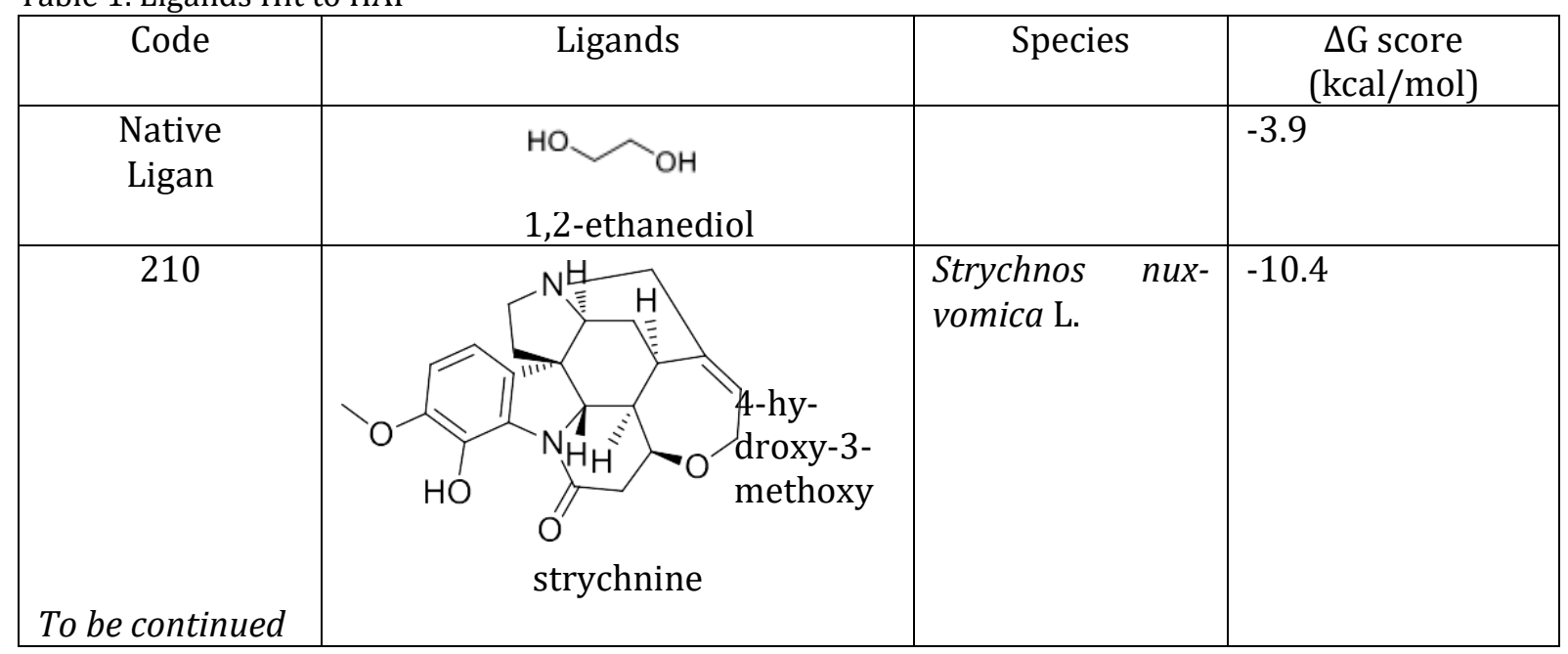




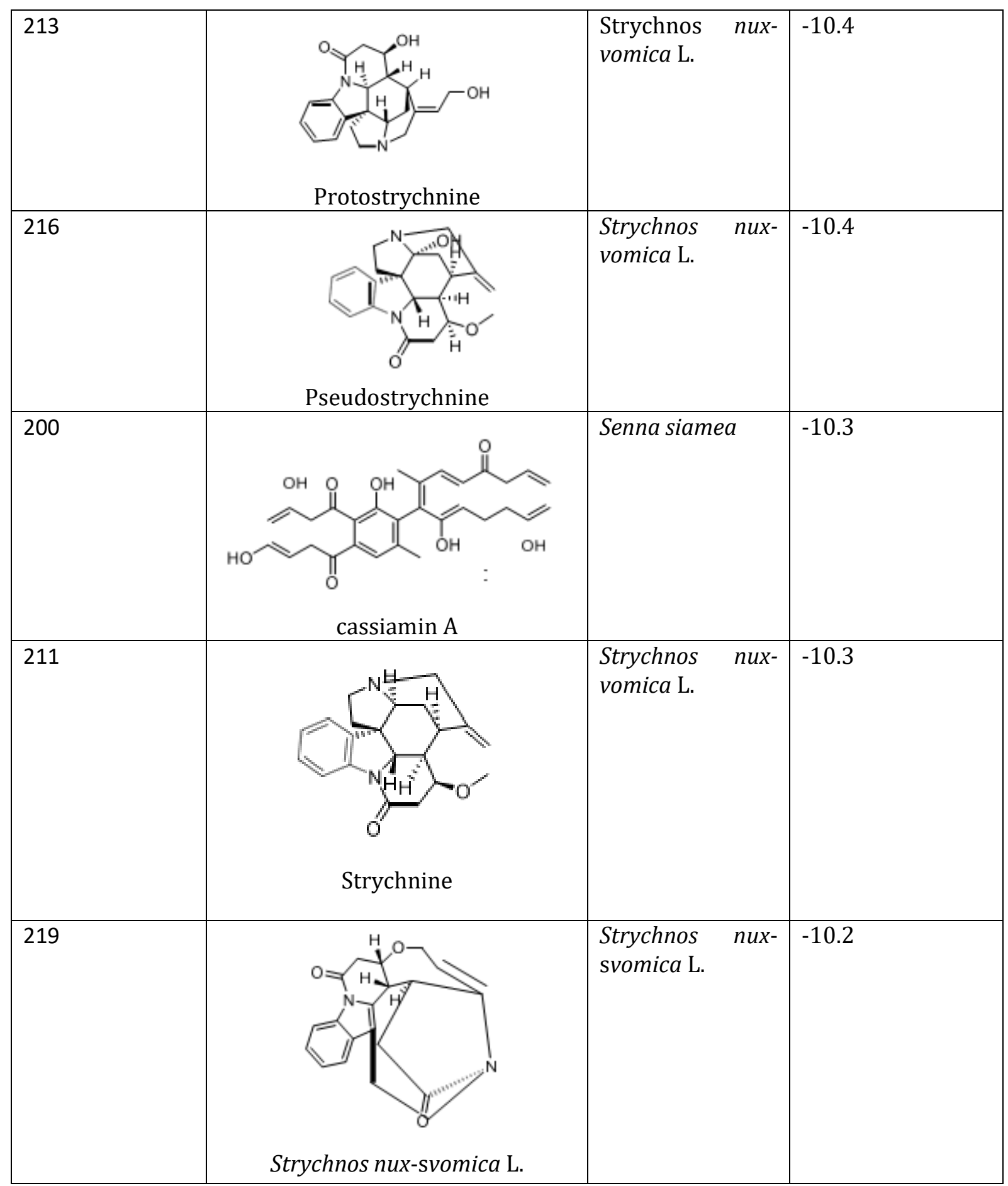

From table 1 six compounds have a great $\Delta$ G score coded AM210, AM213, AM216, AM200, AM211, and AM219. The three top compounds coded AM210, AM213, and AM216 with the best $\Delta \mathrm{G}$ score of $-10.4 \mathrm{kcal} / \mathrm{mol}$, followed by compounds coded AM200 and AM211 which have $\Delta \mathrm{G}$ score of $-10.3 \mathrm{kcal} / \mathrm{mol}$, and the AM219 have $\Delta \mathrm{G}$ score of $-10.2 \mathrm{kcal} / \mathrm{mol}$. The $\Delta \mathrm{G}$ value of these compounds is greater than the native ligand (1,2-ethanediol) which is only $-3.9 \mathrm{kcal} / \mathrm{mol}$. With this $\Delta \mathrm{G}$ score, these compounds can replace the native ligand from the HAP enzyme to inhibit the degradation of hemoglobin in the erythrocytic stage. When the hemoglobin degradation process 
by Plasmodium falciparum is inhibited, amino acids cannot be produced so the process of biosynthesis and energy metabolism will be disrupted. Subsequent is a visualization of the interaction between three top compounds on HAP enzymes (Figure 1, 2, 3, and 4).

Six compounds with great $\Delta \mathrm{G}$ score were constituents of two Indonesian medicinal plant species, Strychnos nux-vomica L. and Senna siamea. Strychnos nux-vomica L. is a plant of the genus Strychnos and family Loganiaceae and Senna siamea is a plant of the genus Senna and family Leguminosae which are commonly used and traditional medicine by Indigenous people of Indonesia. Interestingly, 5 of the 6 best compounds were secondary metabolites of Strychnos nux-vomica L. This strychnos plant is commonly used as a medicinal plant against malaria, especially in the East Nusa Tenggara (NTT) and West Nusa Tenggara (NTB) (Najiyah et al., 2014). The crude extract of the Strychnos Nux-vomica L. and other genus Strychnos has been previously reported as an antiplasmodial agent but limited information regarding its constituent's activity against Plamsodium faciparum (Philippe et al., 2005).

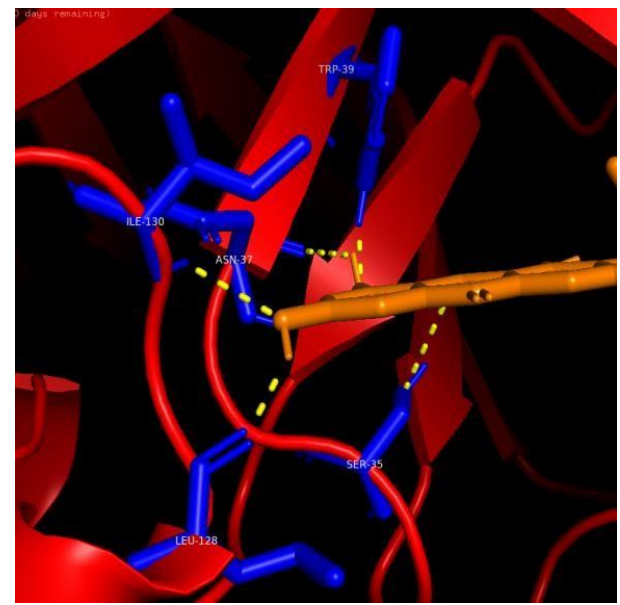

Figure 1. Interaction visualization native ligand against HAP showing hydrogen bonding with ILE130, ASN-37, SER-35, LEU-128, TRP-39

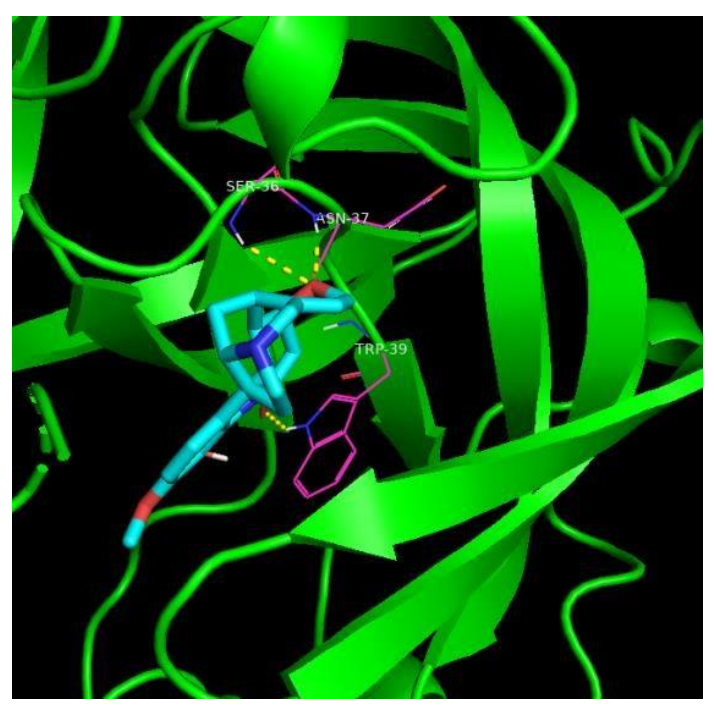

Figure 2. Interaction visualization AM210 against HAP showing hydrogen bonding with SER-36, ASN-37, and TRP-39 


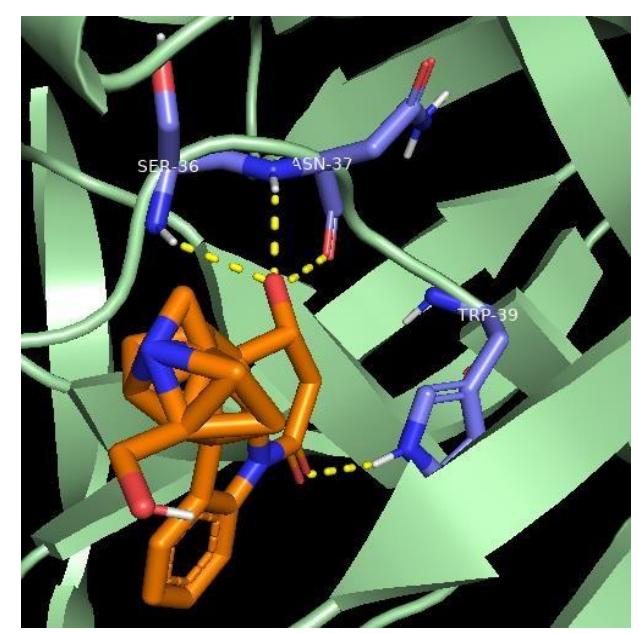

Figure 3. Interaction visualization AM213 against HAP showing hydrogen bonding with SER-36, ASN-37, and TRP-39

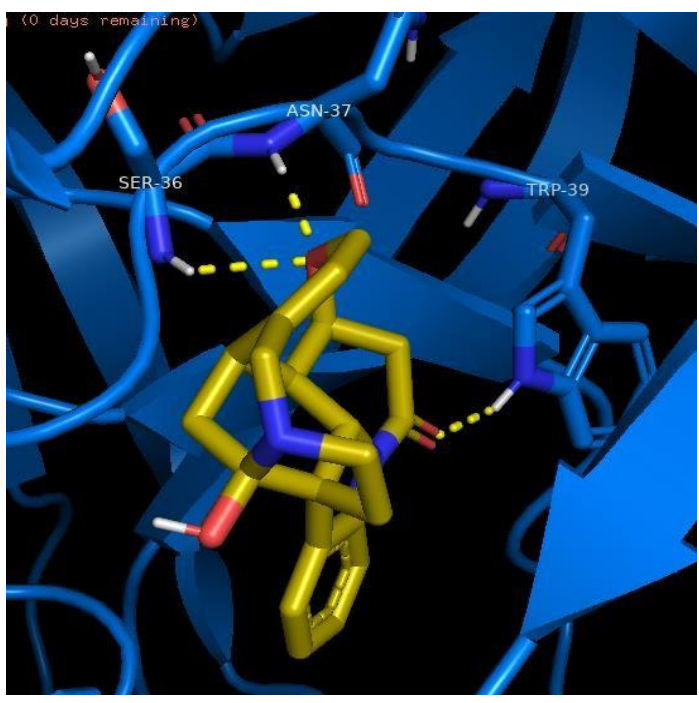

Figure 4. Interaction visualization AM216 against HAP showing hydrogen bonding with SER-36, ASN-37, and TRP-39

Table 2. Amino acid residues

Ligand Amino Acid Residues

Native Ligand

ILE-130, ASN-37, SER-35, LEU-128, TRP-39

AM210

SER-36, ASN-37, TRP-39

Besides the $\Delta G$ score, the results of molecular docking were also studied from the binding site between the hydrogen bonds and the amino acids of the HAP enzyme. Both native ligand and the three top molecules attached to two similar amino acid residues, ASN-37 and TRP-39. On the other hand AM210, AM213, and AM216 which are compounds from Strychnos nux-vomica L. plants have 
the same binding site, SER-36, ASN-37, and TRP-39. The AM210, AM213, and AM216 compounds have the same $\Delta G$ score and binding site, this is due to the structure of these three compounds are similar (Table 2).

This study found six potential compounds from 283 compounds with the top three of them included in the same species, Strychnos nux-vomica L. This research can be a start discovering antimalarial drug leads as HAP inhibitors from Indonesian medicinal plants.

\section{Conclusion}

Molecular docking experiments of the 238 ethnopharmacological compounds against the HAP structure produced three top hits molecules namely AM210 (4-hydroxy-3-methoxy strychnine), AM213 (protostrychnine), AM214 (vomicine), and AM216 (pseudostrychnine) that are from Strychnos nux-vomica L. and have similar $\Delta \mathrm{G}$ score of $-10.4 \mathrm{kcal} / \mathrm{mol}$ that was higher compared to HAP native ligand. Ethnopharmacology and computer-aided drug screening tandem protocol was successfully discovered antimalarial drug lead as the HAP inhibitor from the Indonesian medicinal plant.

\section{Acknowledgment}

AKP thanks to University of Jember for research support.

\section{References}

Teng, W-C., Suwanarusk, R., Ong, Al., Ho, H-K., Russell, B., Renia, L., \& Koh, H-L. (2019). In vitro antimalarial evaluations and cytotoxicity investigations of Carica papaya leaves and carpaine Natural Product Communications, 14, 33-6, https://doi.org/10.1177/1934578X1901400110

Go M-L. (2005). Novel Antiplasmodial Agents. Medicinal Research Reviews, 23, 456-87

Elyazar, I. R. F., Hay, S. I., \& Baird, J. K. (2011). Malaria distribution, prevalence, drug resistance and control in Indonesia. Advances in Parasitology, 74, 41-175. doi: 10.1016/B978-0-12-385897-9.00002-1.

Erdelen, W. R., Adimihardja, K., \& Moesdarsono, H. (1999). Biodiversity, traditional medicine and the sustainable use of indigenous medicinal plants In Indonesia. Indigenous Knowledge \& Development Monitor, 7, 3-6.

Pramono, E. (2002). The commercial use of traditional knowledge and medicinal plants in Indonesia Multi-Stakeholder Dialogue on Trade, Intellectual Property and Biological Resources in Asia (Rajendrapur, Bangladesh: BRAC Centre for Development Management)

Health Department of Indonesia. (1986). Senarai Tumbuhan Obat Indonesia. Jakarta: Health Department of Indonesia

Ersmark, K., Samuelsson, B., \& Hallberg, A. (2006). Plasmepsins as potential targets for new antimalaria therapy. Medicinal Research Reviews, 26(5), 626-66. doi: 10.1002/med.20082.

Gohlke, H., \& Klebe, G. (2002). Approacges to the description and prediction of the binding affinity of small-molecule ligands to macromolecular receptors Angewandte Chemie International Edition English, 41, 2644-76

Kuntz, I. D., Blaney, J. M., Oatley, S. J., Langridge, R., \& Ferrin, T. E. (1982). Ageometric approach to macromolecule-ligand interaction Journal of Molecular Biology, 161, 269-88

McConkey, B. J., Sobolev, V., \& Edelman, M. (2002). The performance of current methods in ligand- protein docking Current Science,83(7), 845-56

Trott, O., \& Olson, A. J. (2010). Autodock vina: improving the speed and accuracy of docking with a new scoring function, efficient optimization and multi-threading. Journal Computational Chemistry, 31(2), 455- 61. doi: 10.1002/jcc.21334

Pujiastuti, P., Sumarsih, S., Arwati, H., Amalina, I., Fanani, M. Z., Utomo, E. P., Fitri, L. E., Nugraha, A. S., Lie, W., \& Pyne, S. G. (2014). Epicroomine and croomine from stemona tuberosa antimalarial drug for inhibiting dihydrofolate reductase (DHFR) activity and their molecular modeling. Journal of Chemical and Pharmaceutical Research, 6, 544-8

Pratama, M. R. F., \& Aziz, I. R. (2019). Molecular docking of bawang dayak (Eleutherine bulbosa) secondary metabolites as bacterial cell wall synthesis inhibitor $1^{\text {st }}$ International Conference on Science and Technology (Oxford: Elsevier).

Pratama, M. R. F., \& Gusdinar, T. (2017). Between artemisinin and derivatives with neuraminidase: a docking study insight. Asian Journal of Pharmaceutical and Clinical Research, 10(8),1-5. https://doi.org/10.22159/ajpcr.2017.v10i8.18667 
Najiyyah, S. U., Ardiansyah, A., Prayitno, O., Safitri, R. D., \& Ekaputri, N. P. G. M. (2014). Gelas kayu bidara laut (geyu bilut) sebagai antimalaria Prosiding Elektronik (e-Proceeding) PIMNAS Program Kreativitas Mahasiswa-Penelitian (PKM-P). Jakarta: Indonesian Directorate General of Higher Education.

Philippe, G., Angenot, L., De Mol, P., Goffin, E., Hayette, M. P., Tits, M., \& Frederich, M. (2005). In vitro screening of some strychnos spesies for antiplasmodial activity. Journal of Ethnopharmacology, 97(3), 535-9. doi: 10.1016/j.jep.2004.12.011 